\title{
Edge-area form removal of two-process surfaces with valley excluding method approach
}

\author{
Przemystaw Podulka ${ }^{1, *}$ \\ ${ }^{1}$ Rzeszow University of Technology, The Faculty of Mechanical Engineering and Aeronautics, Powstancow Warszawy 12 St., 35-959, \\ Poland
}

\begin{abstract}
This paper analyses the influence of edge-area form removal on surface texture parameters (from ISO 25178 standard). The study focused on assessing the effect of near-edge dimples on surface texture analysis. Areal form removal was performed by means of digital filtering methods (regular Gaussian filter, robust Gaussian regression filter, median filter and/or other algorithms). For minimisation of dimples distortion the valley digital excluding method $\left(\mathrm{V}_{\mathrm{DEM}}\right)$ with standard deviation determination procedure was applied to measure plateau-honed cylinder liner surfaces (more than 20 measured and/or 20 with digitally added dimples surfaces were studied). The measurements were performed with a stylus instrument, Talyscan 150, or a white light interferometer, Talysurf CCI Lite. It was assumed that application of $V_{\text {DEM }}$ with further application of proposed digital filtering algorithms caused the decrease in dimples distortion with accordance to regular Gaussian regression and/or robust Gaussian regression filtering methods. It was also found that the near-edge dimples were more vulnerable to distortion than the centre-located oil pockets.
\end{abstract}

\section{Introduction}

Internal combustion engines are widely used in many applications. Assessment of properties of this type of elements is of a great importance especially from the perspective of their contribution to air pollution, reduction of fuel consumption and emissions.

Plateau honed cylinder liner surface is an example of surface texture which consists of smooth plateaus with deep and/or wide pockets. This type of surface is characterised by good sliding properties and lubricant retention; surfaces containing dimples have a definite advantage over one-process surfaces [1-4].

Accurate surface topography measurements and analysis are crucial for functional properties of surfaces (sealing, friction, lubricant etc). There are many determinants affecting uncertainty in surface geometry measurements caused by the environment and measurements: equipment, object, software and method [5-11].

Surface topography parameters are usually calculated after form removal [12]. Selection of reference plane (surface topography analysis) is performed by means of: least square fitting algorithms [13-15], polynomials [1617], Gaussian regression [18] and/or robust Gaussian regression filters [19], splines [20], morphological algorithms [21-22], wavelet [23] and other methods [2425]. Areal form removal of the two-process surface is of great importance, and therefore, a number of algorithms and/or procedures are suggested. However, the selection of reference plane with close attention to the dimple size and distribution has not been accurately defined.

There is an extensive body of literature considering areal form removal of two-process surfaces [26-27]. The main scheme of selection of the reference plane of the two-process surface was to minimise the distortion of edge-situated oil pockets and/or dimples/valleys. Certain aspects of edge-effect problem elimination by a recursive implementation of Gaussian and/or edge-area form removal by means of various robust processing techniques were also taken into consideration in [28].

In this paper proposes the valley excluding method. For areal form removal various digital filtering methods are introduced and compared with commonly used procedures (polynomial approximation or filtering techniques: Gaussian regression and/or robust Gaussian regression schemes).

\section{Materials and methods}

In this paper, the cylinder liner surfaces after the plateauhoning process with burnished dimples were taken into consideration. More than 20 measurements and 20 modelled surfaces were analysed, however only a few were shown in detail.

The tests were conducted by means of the following measuring equipment: stylus instrument Talyscan 150 (nominal tip radius about $2 \mu \mathrm{m}$, height resolution about 10 $\mathrm{nm}$ ) and/or white light interferometer Talysurf CCI Lite

${ }^{*}$ Corresponding author: p.podulka@prz.edu.pl 
(height resolution $0.01 \mathrm{~nm}$ ). The measured area was $5 \mathrm{~mm}$ by $5 \mathrm{~mm}$, the spacing was between 5 and $15 \mu \mathrm{m}$. The measurement was repeated three times and average values were taken into account (a method for surface measurement uncertainty determination was applied).

For areal form removal we propose: polynomials of $2^{N D}\left(P_{2 N D}\right)$ and $4^{T H}\left(P_{4 T H}\right)$ degrees and the following types of schemes: Gaussian regression $\left(F_{G R}\right)$ and robust Gaussian regression $\left(F_{R G R}\right)$ filters, median $\left(F_{M E}\right)$ filter, Haar Wavelet $\left(F_{H W}\right)$, Mexican Hat Wavelet $\left(F_{M H W}\right)$, Morlet Wavelet $\left(F_{M O W}\right)$ and Meyer Wavelet $\left(F_{M E W}\right)$.

For minimisation of dimple distortion, the valley digital excluding method $\left(V_{D E M}\right)$ is employed. The dimples were detected by calculation of standard deviation for each measured point relative to eight neighbouring points. The value of standard deviation was defined for longitudinal profiles. When valleys/dimples were distinguished then were digitally filled by smooth shape. For details with excluded valleys, various filtering methods were applied and compared.

In the study we accounted for the influence of commonly used algorithms and/or $V_{D E M}$ on the selection of reference plane and/or surface topography parameters (from ISO 25178 standard).

a)

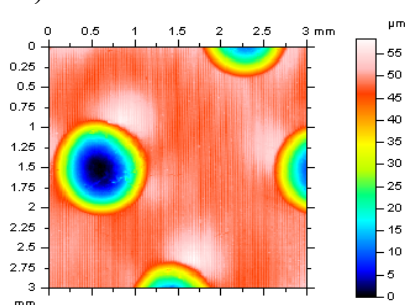

d)

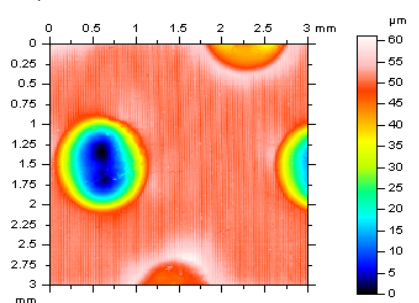

b)

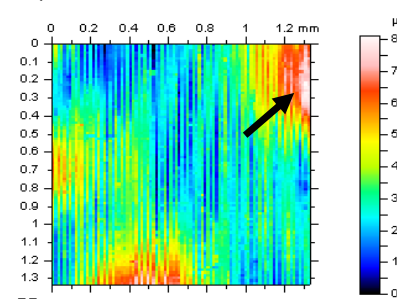

e)

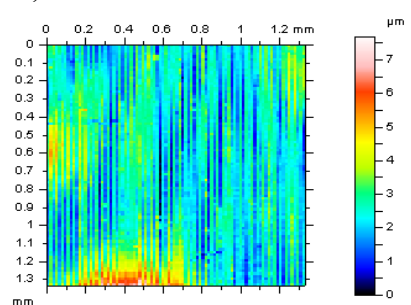

\section{Results and discussions}

It was assumed that dimple distortion after application of $\mathrm{P}_{4 \mathrm{TH}}$ was smaller than after $F_{R G R}$; robust filtering caused the flattening of valleys (Figure 1-d and 1-f). The flattening of dimples increased when the distance between the valley and edge of the analysed surface.

When distortion of valleys is taken into consideration, in certain cases application of polynomials gives better results than robust techniques (Figure 2). However, for areas free of dimples (plateau-part of the surface), smaller values of $S q$ (root mean square height), $S v$ (maximum valley depth), $S z$ (maximum height) and $S a$ (arithmetic mean height) parameters were obtained when $F_{R G R}$ was applied (in accordance to $P_{4 T H}$ ). The position of the reference plane in some of the near-valley areas was not accurately estimated (it was indicated by the arrows in Figure 1-b or 1-c) when polynomials were used. The application of commonly used algorithms did not allow removing the form correctly when surface contained deep and wide dimples $\left(P_{4 T H}\right)$ and/or valleys were edgesituated $\left(F_{R G R}\right)$. Therefore, $V_{D E M}$ with various filtering procedures was proposed.

Fig. 1. Plateau-honed cylinder surface with additionally added oil pockets after form removal with $P_{4 T H}\left(\mathrm{a}, \mathrm{b}\right.$ and $\mathrm{c}$ ) or $F_{R G R}$ with $F_{C O}=0.8 \mathrm{~mm}(\mathrm{~d}, \mathrm{e}$ and $\mathrm{f})$ : isometric views (a, d), extracted details (b, e) and profiles (c, f) with respective parameters of extracted details.

a)

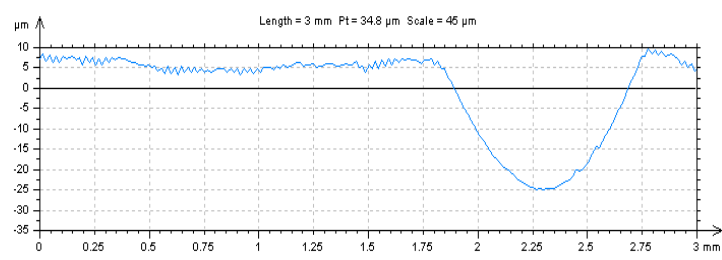

c)

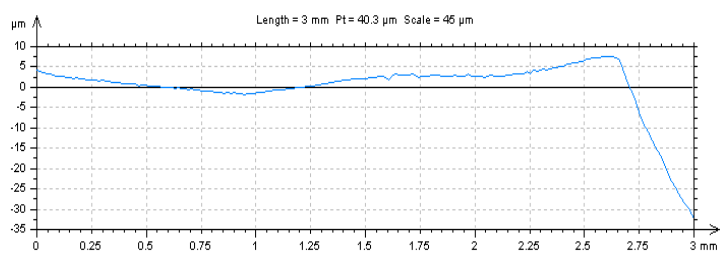

b)

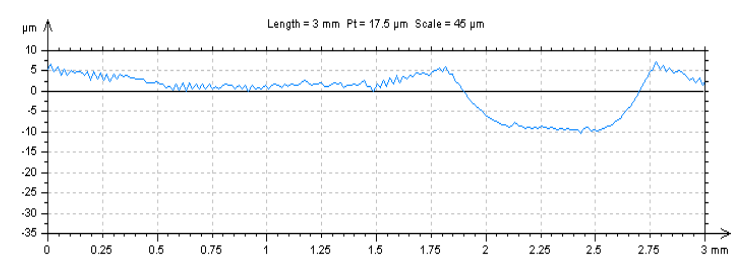

d)

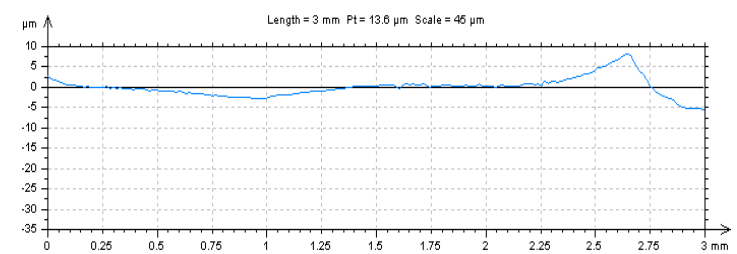

Fig. 2. Profiles extracted from surface after form removal with: $P_{4 T H}(\mathrm{a}, \mathrm{c})$ and $F_{R G R}$ with $F_{C O}=0.8 \mathrm{~mm}$ (b, d). 
The distortion of the reference plane and/or valleys increased when the degree of polynomials increased; when the biggest degree of polynomial was applied, the biggest distortion of dimples occurred (the maximum profile height $P t$ increased when the degree of polynomial was enlarged). Application of $V_{D E M}$ and then polynomials (from $2^{N D}$ to $4^{T H}$ degree) caused a decrease of reference plane distortion in comparison with the use of polynomials alone (Figure 3 ). When $V_{D E M}$ was applied, the results after application of $2^{N D}$ or $4^{T H}$ degree did not exist or were negligible. When $F_{G R}$ alone was used, the flatness of dimples occurred (Figure 3-e); when the smallest distance between dimple and edge of an analysed detail was received, the biggest distortion was observed. The value of $P t$ parameter decreased by more than $100 \%$ in some cases (compared to polynomial usage). Application of $V_{D E M}$ followed by $F_{G R}$ resulted in minimising the valley and/or reference plane distortions (Figure 3-f).

Extracted details after form removal by $V_{D E M}$ and further application of: $F_{M E}(\mathrm{a}), F_{G R}(\mathrm{~d}), F_{H W}(\mathrm{~g}), F_{M H W}(\mathrm{j})$, $F_{M E W}(\mathrm{~m})$ are presented in Figure 4. From isometric view analysis, it was assumed that usage of $F_{M E}, F_{H W}$ and $F_{M E W}$ gave better results than $F_{G R}$ or $F_{M H W}$; the plateau-part of studied detail seemed to be more flattened. Moreover, the distortion/flatness of dimples was minimised and/or it was negligible (it can be precisely observed with profile analysis).

However, the minimal value of core roughness depth $S k$ was obtained when $F_{M E}$ was used; when $F_{H M}, F_{M E W}$ were applied the value of $S k$ parameter was overestimated around $100 \%$ and $50 \%$ respectively (in accordance to $F_{M E}$ ). The minimal (maximal) value of reduced peak
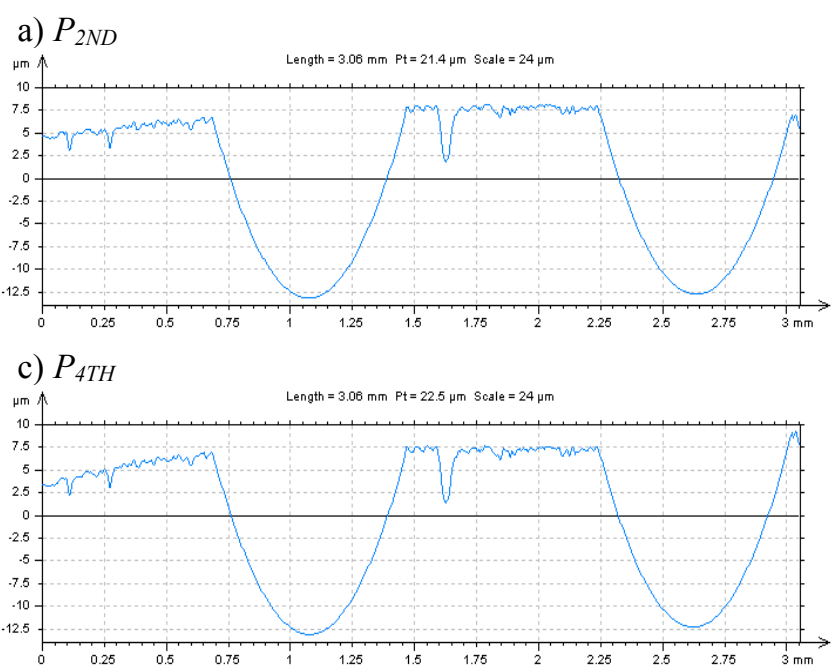

e) $F_{G R}, F_{C O}=0.8 \mathrm{~mm}$

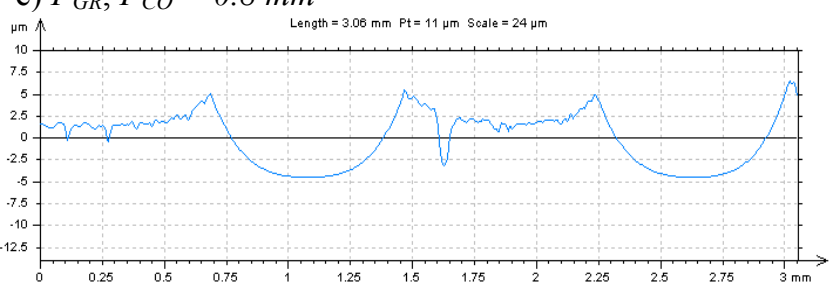

height (reduced valley depth) $S p k(S v k)$ was obtained with $F_{H W}$ appliance. However, when the sum of $S k$ and $S p k$ parameters values were taken into consideration, the minimum was received for $F_{M E}$ filtering. The minimal (maximal) values of $S q$, Sa and $S p$ ( $S v$ and $S z$ ) parameters were obtained using $F_{H W}$. However, the minimal value of $P t$ parameter was received when $F_{M E}$ was applied.

Application of $F_{G R}, F_{H W}, F_{M H W}$ caused a distortion of near-dimple areas (as indicated by arrows in Figure 4); the biggest exaggeration of near-valley areas occurred when the biggest value of $P t$ parameter was obtained. From profile analysis, it could be seen that the application of $F_{G R}$ causes substantial distortion of near-valley areas of the studied details.

For the selection of procedure for surface topography form removal, the free-of-dimple details were taken into consideration (Figure 5). From the analysis of isometric view of extracted details, it was assumed that application of $F_{G R}, F_{M H}, F_{M O W}$ caused noticeable distortion of nearvalley areas (it was indicated by the arrows in Figure 5-b, 5-d and 5-e). Application of $V_{D E M}$ with $F_{M E}$ caused minimisation of values of height parameters $(S q, S p, S v$, $S z$ and $S a$ ) with reference to the $F_{G R}, F_{H M}, F_{M H W}, F_{M O W}$ and $F_{M E W}$ filtering methods; in accordance with the commonly used $F_{G R}$, the values of most of the height parameters (except of $S v$ parameter) decreased by approx. (or in some cases more than) $50 \%$. The minimal (maximal) value of $S s k(S k u)$ parameter was obtained when $V_{D E M}$ with $F_{M E W}$ were applied.

It was assumed that the effect of dimple distribution (near-edge valley location) on areal form removal (distortion of dimples and/or reference plane position) was minimised when $V_{D E M}$ was applied.

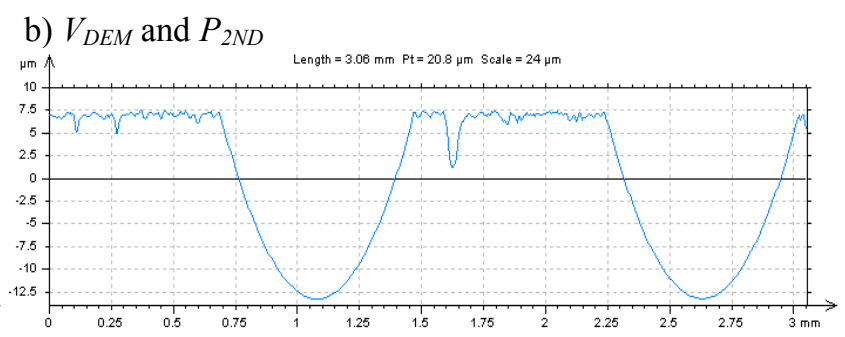

d) $V_{D E M}$ and $P_{4 T H}$
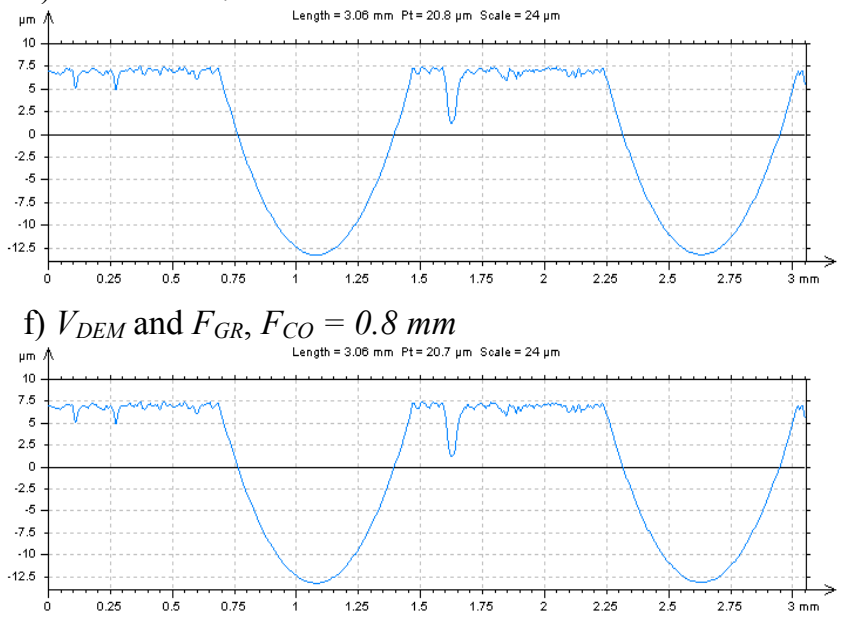

Fig. 3. Extracted profiles from surfaces after form removal with: regular methods (a, c and e) and procedure with excluded valleys (b, d and f). 
a)

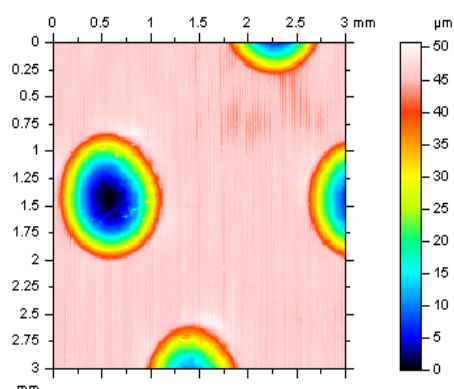

d)

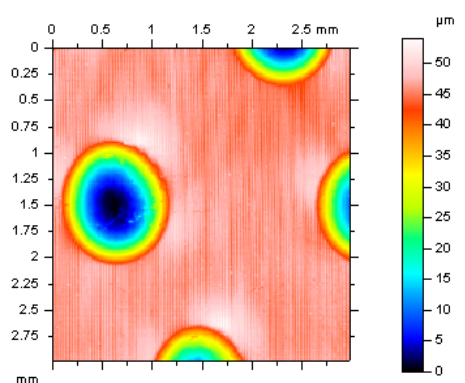

g)

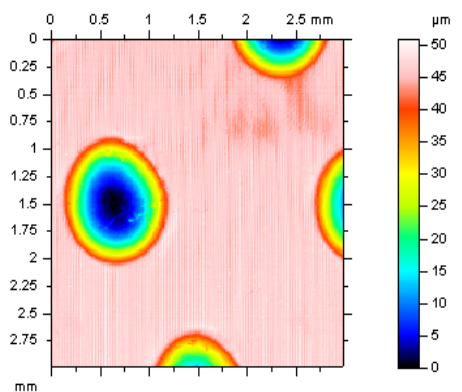

j)

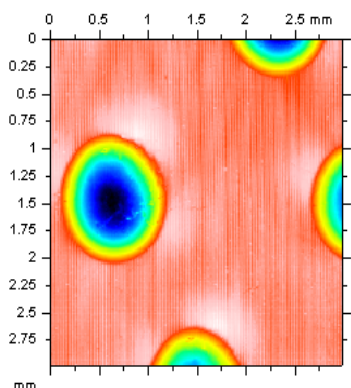

$\mathrm{m})$
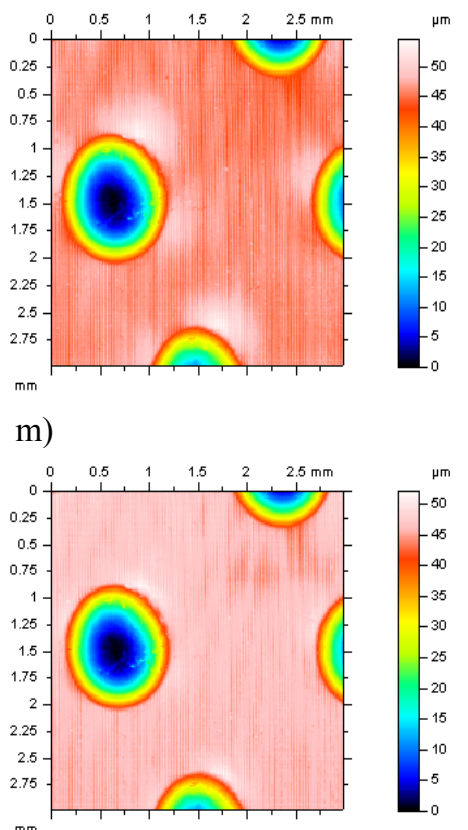

b)

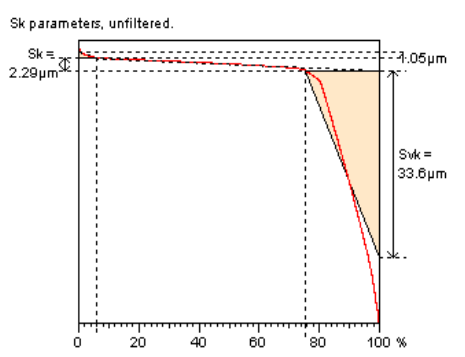

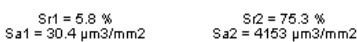

e)

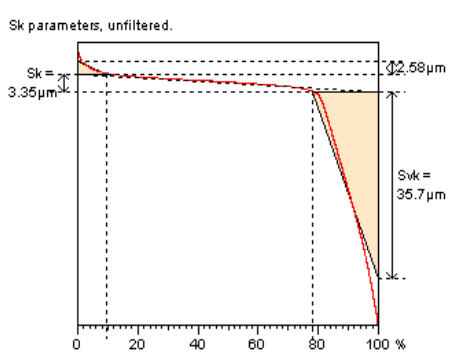

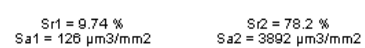

h)

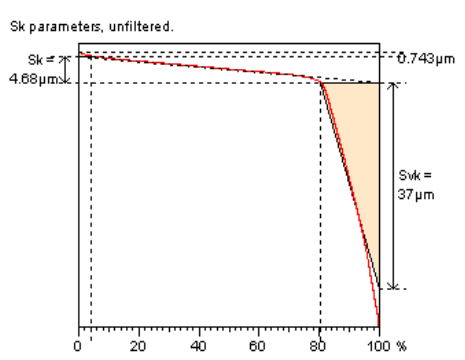

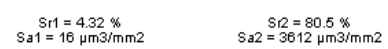

$\mathrm{k})$

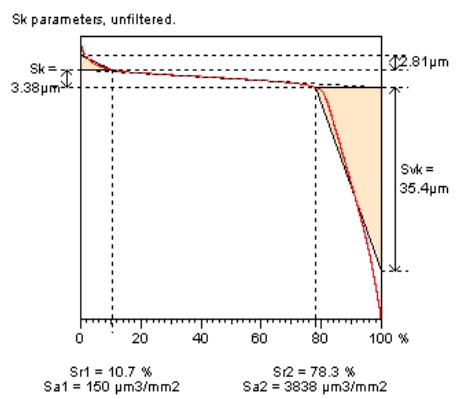

n)

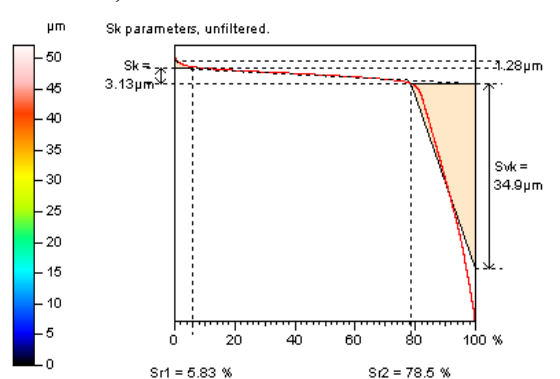

c)

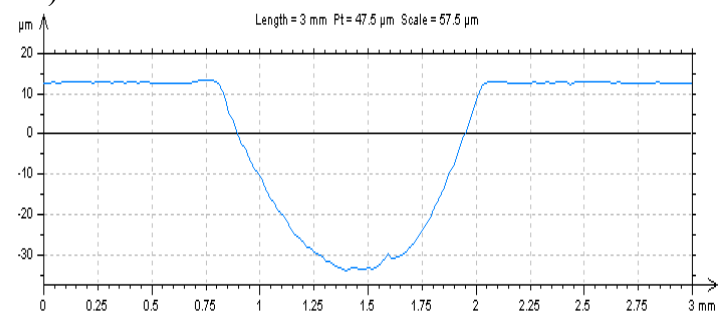

$S q=10.3 \mu \mathrm{m}, S s k=-2.37, S k u=7.6, S p=8.55 \mu \mathrm{m}$, $S v=42.20 \mu \mathrm{m}, S z=50.80 \mu \mathrm{m}, S a=7.00 \mu \mathrm{m}$

f)

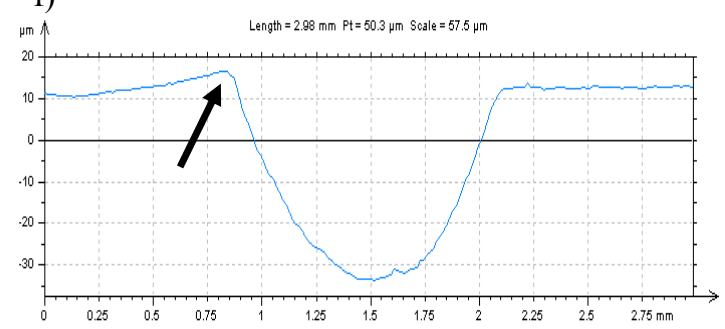

$S q=10.3 \mu \mathrm{m}, S s k=-2.38, S k u=7.77, S p=11.60 \mu \mathrm{m}$, $S v=42.40 \mu \mathrm{m}, S z=54.00 \mu \mathrm{m}, S a=6.93 \mu \mathrm{m}$

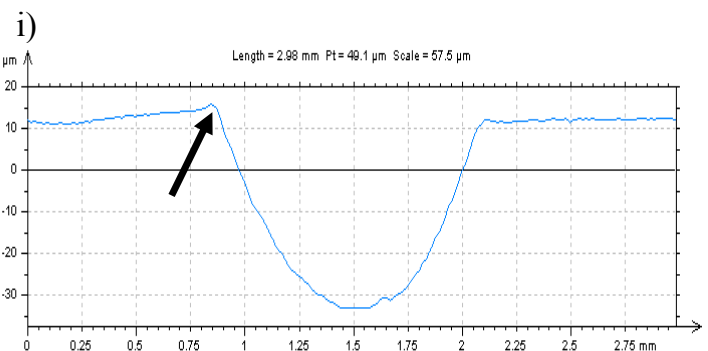

$S q=10.1 \mu \mathrm{m}, S s k=-2.47, S k u=8.2, S p=8.11 \mu \mathrm{m}$, $S v=42.60 \mu \mathrm{m}, S z=50.71 \mu \mathrm{m}, \mathrm{Sa}=6.71 \mu \mathrm{m}$

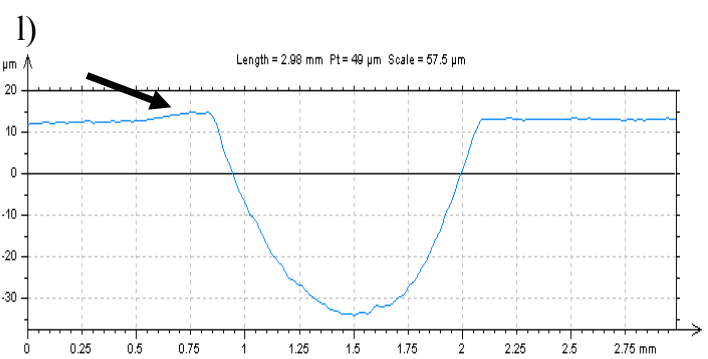

$S q=10.3 \mu \mathrm{m}, S s k=-2.39, S k u=7.84, S p=12.00 \mu \mathrm{m}$, $S v=42.50 \mu \mathrm{m}, S z=54.50 \mu \mathrm{m}, S a=6.87 \mu \mathrm{m}$

o)

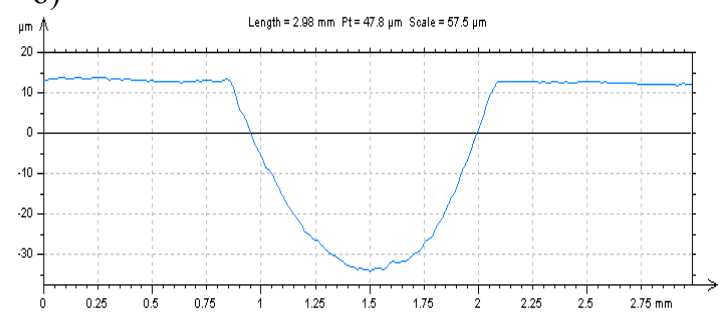

$S q=10.0 \mu m, S s k=-2.5, S k u=8.35, S p=9.58 \mu m$, $S v=42.50 \mu \mathrm{m}, S z=52.10 \mu \mathrm{m}, S a=6.84 \mu \mathrm{m}$

Fig. 4. Isometric views (a, d, g, j and m), material ratio curves (b, e, h, k and n) and profiles with selected parameters (c, f, i, 1 and o) of extracted detail from cylinder liner surface respectively, after form removal by application of $V_{D E M}$ with various digital filtering methods: $F_{M E}(\mathrm{a}-\mathrm{c}), F_{G R}(\mathrm{~d}-\mathrm{f}), F_{H W}(\mathrm{~g}-\mathrm{i}), F_{M H W}(\mathrm{j}-\mathrm{l})$ and $F_{M E W}(\mathrm{~m}-\mathrm{o})$. 
a) $F_{M E}$

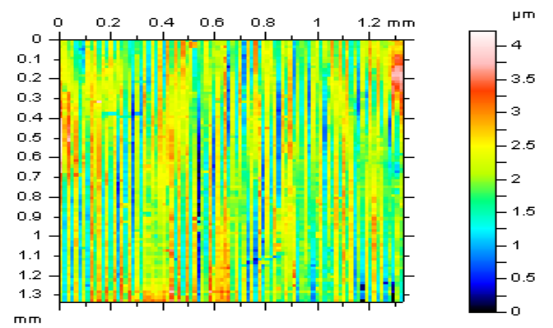

$S q=0.610 \mu m, S s k=-0.218, S k u=2.83$,

$S p=2.20 \mu \mathrm{m}, S v=2.03 \mu \mathrm{m}$,

$S z=4.23 \mu \mathrm{m}, \mathrm{Sa}=0.500 \mu \mathrm{m}$

d) $F_{M H W}$

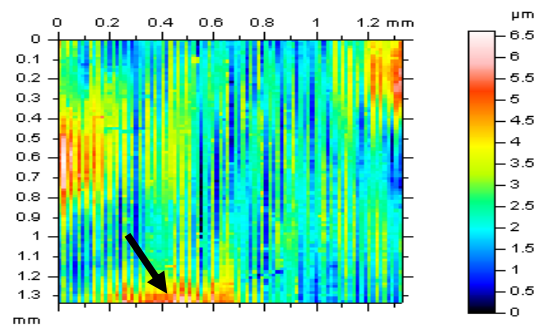

$S q=0.970 \mu \mathrm{m}, S s k=0.492, S k u=3.62$,

$S p=4.10 \mu \mathrm{m}, S v=2.52 \mu \mathrm{m}$,

$S z=6.63 \mu \mathrm{m}, \mathrm{Sa}=0.756 \mu \mathrm{m}$ b) $F_{G R}$

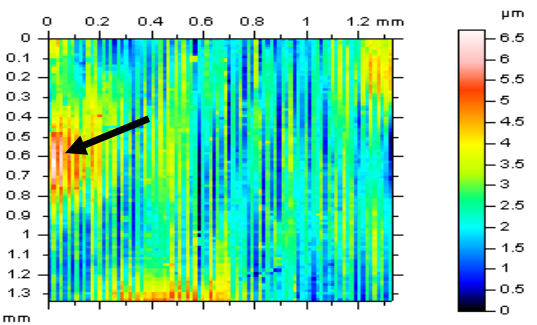

$S q=0.927 \mu m, S s k=0.401, S k u=3.65$,

$S p=4.22 \mu \mathrm{m}, S v=2.48 \mu \mathrm{m}$,

$S z=6.70 \mu \mathrm{m}, \mathrm{Sa}=0.729 \mu \mathrm{m}$

e) $F_{M O W}$

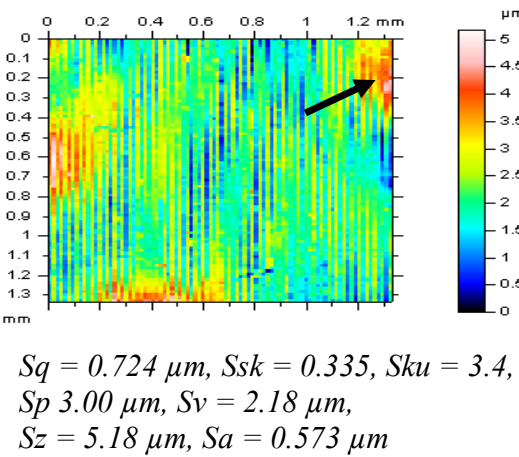

c) $F_{H W}$

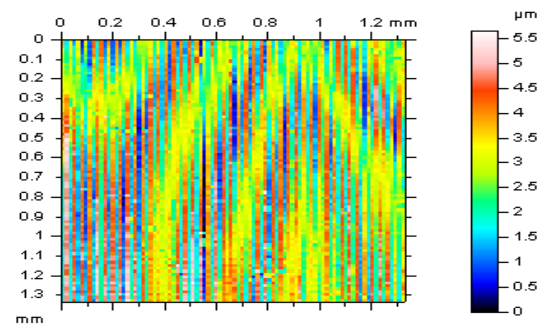

$S q=1.160 \mu \mathrm{m}, \mathrm{Ss} k=-0.0863, S k u=1.98$,

$S p=2.71 \mu \mathrm{m}, S v=2.94 \mu \mathrm{m}$,

$S z=5.65 \mu \mathrm{m}, \mathrm{Sa}=0.995 \mu \mathrm{m}$

f) $F_{M E W}$

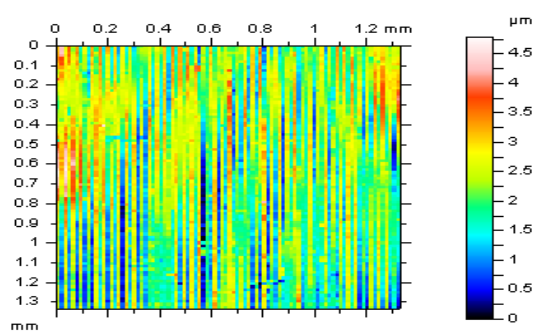

$S q=0.745 \mu m, S s k=-0.158, S k u=2.65$,

$S p=2.66 \mu \mathrm{m}, S v=2.13 \mu \mathrm{m}$,

$S z=4.79 \mu \mathrm{m}, \mathrm{Sa}=0.613 \mu \mathrm{m}$

Fig. 5. Extracted near-dimple details (and their parameters respectively) from surfaceafter form removal with $V_{D E M}$ and various pre-processing methods; $F_{C O}=0.8 \mathrm{~mm}$.

\section{Conclusions}

The following conclusions and/or remarks conclude the study:

1. Dimple distortion after application of $P_{4 T H}$ was smaller than after usage of $F_{R G R}$; robust filtering caused the flattener of valleys; the distortion of dimples increased when the valley-to-edge distance decreased. In certain cases, the application of polynomials gives better results than robust techniques. However, for free-ofdimple areas (plateau-part of analysed detail), smaller values of some height parameters were received when $F_{R G R}$ was applied (in accordance to $P_{4 T H}$ ); the position of the reference plane in certain near-valley areas was not accurately estimated when polynomials were applied.

2. Application of $V_{D E M}$ with polynomials from $2^{N D}$ to $4^{T H}$ degree caused the decrease of distortion of reference plane in accordance to the same usage of polynomials. When $V_{D E M}$ was proposed, the results of surface topography parameter calculation and/or selection of the reference plane after application of $2^{N D}$ or $4^{T H}$ degree of polynomials did not exist or were negligible. When the same $F_{G R}$ was applied, the flatness of dimples was noticeable; the smallest dimple-to-edge distances coincided with the biggest distortions.

3. The application of $V_{D E M}$ and further usage of digital filtering $\left(F_{M E}, F_{G R}, F_{H W}, F_{M H W}, F_{M O W}, F_{M E W}\right)$ allowed minimising the valley and/or reference plane distortions. It was assumed that usage of $F_{M E}, F_{H W}$ and $F_{M E W}$ gave better results than $F_{G R}$ or $F_{M H W}$; the plateaupart of surface seemed to be more flattened. From the analysis of the extracted profiles the distortion/flatness of dimples/position of reference plane were minimised and/or negligible.

4. The minimal value of $S k$ parameter was obtained when $F_{M E}$ was used; the minimum amount of sum of $S k$ and $S p k$ parameters values was received for $F_{M E}$ filtering. Application of $F_{G R}, F_{H W}, F_{M H W}$ caused a distortion of near-valley areas; the biggest exaggeration of neardimple areas occurred when the biggest value of $P t$ parameter was obtained. It was also found that the application of $F_{G R}$ causes substantial distortion in near-valley areas of studied details.

5. Application of $V_{D E M}$ with $F_{M E}$ caused a minimisation of height parameter values, such as: $S q, S p, S v, S z$ and Sa (compared to the $F_{G R}, F_{H M}, F_{M H W}, F_{M O W}$ and $F_{M E W}$ filtering methods); the values of the height parameters decreased in some cases more than $50 \%$.

6. It was found that application of the $V_{D E M}$ caused the minimisation of distortion of the reference plane/nearedge areas and/or near-edge distributed oil pockets. Moreover, for areal form removal of cylinder liner surfaces containing deep and wide dimples with nearedge distribution, it is recommended to use the $V_{D E M}$ with various median filtering methods (e.g. $F_{M E}$ ).

7. Digital algorithms (filters, wavelets) with $V_{D E M}$ instead of regular procedures (cylinder fitting, polynomials) are recommended for areal form removal of plateau-honed cylinder surfaces containing deep and/or wide oil pockets. False estimation (calculation) of the reference plane (surface texture parameters, such as core roughness depth $S k$, reduced summit height $S p k$ reduced valley depth $S v k$, skewness 
Ssk and/or kurtosis $S k u$ ) can potentially cause a misclassification of properly made parts as lacks, leading to their rejection. Therefore, the selection of a procedure for areal form removal is of great importance.

This paper was prepared with financial support from the project no. 2013/09/N/ST8/04333 from National Science Centre.

\section{References}

1. Y. Jeng, Tribol. T. 39(2), 354-356 (1996)

2. A. Dzierwa, P. Pawlus and W. Żelasko, Proc. Inst. Mech. Eng. B J. Eng. Manuf. 228(10), 1195-1210 (2014)

3. W. Graboń, P. Pawlus, J. Sęp, Tribol. Int. 43(10), 1882-92 (2010)

4. P. Pawlus, Tribol. Int. 26(1), 49-55 (1993)

5. K.J. Stout, (ed), Three-dimensional surface topography - measurement, interpretation and application. (Penton Press, London, 1994)

6. T.R. Thomas, Rough Surfaces. Second Edition. (Imperial College Press, London, 1999)

7. D.J. Whitehouse, Surfaces and Their Measurement. (Hermes Penton, London, 2001)

8. L. Blunt, X. Jiang (ed.)., Advanced Techniques for Assessment of Surface Topography. (Kogan Pages, London, 2003)

9. P. Podulka, P. Pawlus, P. Dobrzański, A. Lenart, J. Phys. Conf. Ser. 483(1), 012025 (2014)

10. M. Magdziak, Aircr. Eng. Aerosp. Tec., 89(6), 953959 (2017)

11. T. Miller, S. Adamczak, J. Świderski, M. Wieczorowski, A. Łętocha, B. Gapiński, Bull. Pol. Ac.: Tech. 65(1), 53-62 (2017)

12. P. Podulka, P. Dobrzański, P. Pawlus, A. Lenart, Metrol. Meas. Syst. 21(2), 247-256 (2014)
13. A.B. Forbes, Least squares best fit geometric elements, NLP report DITC 40 (89), Teddington, UK, (1989)

14. A.B. Forbes, Characterisation of Areal Surface Texture (Springer, 107-128, 2013)

15. P. Podulka, Adv. Sci. Technol. Res. J.; 10(30), 164175 (2016)

16. P.J. Sullivan, Metrology and Properties of Engineering Surfaces (Springer, 2001)

17. K.J. Stout, P.J. Sullivan, W.P. Dong, E. Mainsah, N. Luo, T. Mathia, H. Zahouani, Publication EUR 15178 EN Commission of the European Communities, (1993)

18. S. Brinkmann, H. Bodschwinna, H.-W. Lemke, Int. J. Mach. Tool. Manu. 41(13-14), 2153-2161 (2001)

19. S. Brinkman, H. Bodschwinna, Advanced Techniques for Assessment Surface Topography (Elsevier, 2000)

20. B. Muralikrishnan, J. Raja: Computational surface and roundness metrology (Springer, 2009)

21. S. Lou, X. Jiang, PJ. Scott, J. Phys. Conf. Ser., 483, 012020 (2014)

22. J. Józwik, D. Ostrowski, R. Milczarczyk, G.M. Krolczyk, J. Braz. Soc. Mech. Sci. Eng. 40, 215 (2018)

23. L. De Chiffre, P. Lonardo, H. Trumpold, D.A. Lucca, G. Goch, C.A. Brown, J. Raja, H.N. Hansen, CIRP Ann.-Manuf. Techn. 2, 635-642, 644-652, (2000)

24. M. Novak, N. Naprstkova, J. Jozwik, Adv. Sci. Technol. Res. J. 9(26), 41-48 (2015)

25. E. Feldshtein, J. Józwik, S. Legutko, Adv. Sci. Technol. Res. J. 10(30), 144-149 (2016)

26. Y.-B. Yuan, X.-F. Qiang, J.-F.Song, T.V. Vorburger, Precis. Eng. 24(1), 62-69 (2000)

27. Y.-B Yuan, W.-Y. Piao, J.-B. Xu, J. Phys. Conf. Ser. 48, 1401-1406 (2006)

28. D. Janecki, Precis. Eng. 36, 128-136 (2012) 